\title{
COUPLING REACTIONS BETWEEN FLAVYLIUM IONS AND CATECHIN
}

\author{
Teresa Escribano-Bailón, Olivier Dangles and Raymond Brouillard*
}

Laboratoire de Chimie des Polyphénols, associé au CNRS, Université Louis Pasteur, Facultẻ de Chimie, 1, rue Blaise Pascal, 67008 Strasbourg, France

(Received 31 July 1995)

Key Word Index-anthocyanins; tannins; flavylium ions; catechin; acetaldehyde; copigmentation: self-association; red wine pigments.

\begin{abstract}
In order to model natural polymeric pigments present in old red wines, new covalent adducts have been synthesized upon condensation of synthetic flavylium ions (models of anthocyanins) with catechin (model of tannins) in the presence and in the absence of acetaldehyde. These new pigments have been investigated by 1D and 2D NMR, HPLC, FAB-mass and UV-visible spectroscopies and molecular modelling. The two flavylium salts used in this work (3,4'-dimethoxy-7-hydroxyflavylium chloride and 5,7-dihydroxy-3,4'-dimethoxyflavylium chloride) display quite different reactivities toward catechin. The electronic donating effect of the catechin moiety and the formation of noncovalent dimers in acidic aqueous or methanolic solution should be mainly responsible for the improved stability of the flavylium chromophore in the new pigments.
\end{abstract}

\section{INTRODUCTION}

Anthocyanins are natural pigments from the polyphenol family that are largely responsible for the red, blue and purple colours displayed by flowers and fruits. Being present in the skin of grapes, they give their colour to young red wines. Paradoxically, most anthocyanins turn into colourless compounds when extracted from their natural medium and dissolved into an aqueous solution of comparable acidity. Indeed, the flavylium ion, which is the main coloured form of anthocyanins, undergoes the nucleophilic attack of water and is reversibly converted into a colourless hemiacetal according to a chemical reaction called hydration of the flavylium ion. Fortunately, this colour loss is not definitive owing to complexation phenomena selectively involving the flavylium ion and efficiently competing with the flavylium-hemiacetal conversion. For instance, colourless polyphenols present in the natural medium of anthocyanins (benzoic and cinnamic acid derivatives, tannins, flavones and flavonols) are able to interact with the planar $\pi$-electronrich flavylium nucleus through their phenolic moiety and form noncovalent adducts upon hydrophobic stacking, as demonstrated from in vitro investigations [1]. This molecular complexation process, called copigmentation, is instantaneous and is expected to occur in red wines between anthocyanins (pigments) and condensed tannins (copigments). However, the very slow changes in the colour of red wines upon ageing suggest that coupling reactions between anthocyanins and tannins could take

*Author to whom correspondence should be addressed. place and lead to new pigments. In this respect, copigmentation would be the preliminary step toward the formation of a true covalent link between pigment and copigment $[2,3]$. The colour of the new pigments seems much less sensitive to changes in $\mathrm{pH}$ than that of the initial anthocyanins [4, 5], a fact that could account for the increase in colour stability in aged red wines [6-8]

So far, the anthocyanin-tannin covalent adducts have been essentially characterized by their absorption spectra. One of the main purposes of this work is to bring more definitive evidence of their structure. Our strategy consists of mixing a synthetic flavylium ion (model of natural anthocyanin) with (+)-catechin (model of condensed tannin) under appropriate conditions of $\mathrm{pH}$ and temperature, monitoring the coupling reaction by reverse-phase HPLC, isolating the adducts by semi-preparative HPLC and analysing them by mass and UVvisible spectroscopies, 1D and 2D NMR and molecular modelling. In addition, the new pigments will be characterized by their thermal stability, their covalent reactivity with water and their noncovalent dimerization.

\section{RESULTS AND DISCUSSION}

Owing to the partial positive charges born by the flavylium nucleus at the 2- and 4-positions, a flavylium ion is expected to react with nucleophiles. For instance, in weakly acidic aqueous solutions, water itself can react at the 2-position, thus converting the flavylium ion into a colourless hemiacetal. On the other hand, a range of organic nucleophiles, especially electron-rich phenolics, have been reported to react at the 4-position of synthetic 
flavylium ions [9] and natural anthocyanins $[4,10]$. Interestingly, phloroglucinol (1,3,5-trihydroxybenzene) and phloroglucinol derivatives such as catechin and other flavan-3-ols have been suggested to further react with anthocyanins and slowly form new pigments having xanthylium chromophores. This hypothesis is essentially supported by an increase in visible absorbance between 400 and $450 \mathrm{~nm}$ which closely parallels that observed in old wines during ageing [2]. According to another hypothesis, such pigments could also form directly from proanthocyanidins $[11,12]$.

It is well known that aldehydes too are able to react with the nucleophilic phloroglucinol ring of catechin in aqueous acidic solutions, even at room temperature [13]. The fact that acetaldehyde may be generated in wines by oxidation of ethanol has led to the suggestion that coupling reactions between anthocyanins and colourless phenolics in red wines upon ageing could be mediated by acetaldehyde [14-16]. Indeed, addition of acetaldehyde to mixtures of anthocyanins and phenolics was shown to promote colour gains and blueing effects easily detected after only a few days $[10,17-20]$. It has been suggested [10] that new flavylium pigments formed whose flavylium moiety would be connected to the catechin moiety through a $\mathrm{CH}_{3}-\mathrm{CH}$ bridge. Such pigments have been detected by HPLC [21-23] and recent data of FAB-mass spectrometry [18] are consistent with the above-mentioned structure, which remains however to be definitively established.

In our experiments, we took (+)-catechin as the simplest model of condensed tannin and synthetic 3-methoxyflavylium ions as models of anthocyanins. The latter choice has several advantages: 3-methoxyflavylium ions are readily available in gram-quantity and the 3-methoxy group conveniently mimics the 3-glycosyloxy substituent common to almost all natural anthocyanin [24]. Finally, 3-methoxyflavylium ions form covalent adducts with catechin faster than the sterically more hindered natural anthocyanins. Moreover, the $\mathrm{pH}$ was adjusted so as to maximize the speed of formation of the new pigments. The two flavylium salts used in this work $\left(3,4^{\prime}\right.$-dimethoxy-7. hydroxyflavylium chloride (1) and 5,7-dihydroxy-3,4'dimethoxyflavylium chloride (2) only differ by the nature of the substituent $(\mathrm{H}$ or $\mathrm{OH})$ at the 5-position. However, 1 and $\mathbf{2}$ display quite different reactivities toward catechin and will be treated separately. Molecular complexation (copigmentation) taking place between flavylium ions and catechin is expected to govern the coupling reaction, especially its regioselectivity. Therefore, copigmentation of 1 and $\mathbf{2}$ with catechin will be considered first.

\section{Flavylium-catechin copigmentation}

When UV-visible spectra of weakly acidic equilibrated solutions of flavylium ions 1 and 2 are recorded with increasing concentrations of catechin, hyperchromic and bathochromic shifts characteristic of copigmentation are observed. By contrast, when the experiments are conducted in strongly acidic conditions $(0.2 \mathrm{M} \mathrm{HCl})$ for which the anthocyanin is in the pure flavylium form, copigmentation is essentially manifested by its bathochromic effect. The value of the flavylium-catechin binding constant was estimated to be $135( \pm 10)$ and $149( \pm 7) \mathrm{M}^{-1}\left(25^{\circ}\right.$; $0.5 \mathrm{M}$ ionic strength) for 1 and 2 , respectively i.e. in the same range as that measured for malvin $\left(185 \mathrm{M}^{-1}\right)$, a naturally occurring anthocyanin [1].

\section{Direct flavylium-catechin coupling}

Coupling with the 3,4'-dimethoxy-7-hydroxyflavylium ion (1). The reaction between (+)-catechin and two equivalents of 1 was monitored by HPLC at $280 \mathrm{~nm}$. The formation of a new pigment (3), whose $\lambda_{\max }$ in water $(476 \mathrm{~nm})$ is $12 \mathrm{~nm}$ lower than that of 1 , was observed. In addition, several colourless products were detected, among them, $p$-methoxybenzoic acid formed by photochemical degradation of 1 [25]. Formation of 3 was very slow and four months were necessary to get enough material for isolation and purification by semi-preparative HPLC. UV-visible and FAB-mass spectroscopies (molecular peak at 571.1) and ${ }^{1} \mathrm{H}$ NMR analysis showed that 3 was a flavylium 1-catechin adduct having a flavylium chromophore, too. Following Jurd [26], we assume that one equivalent of 1 reacts with catechin according to a Friedel-Craft electrophilic substitution and that the corresponding adduct is consecutively oxidized by the second equivalent of 1 to yield 3 . The absence of the characteristic singlet of the $\mathrm{H}-4$ flavylium proton (around $9 \mathrm{ppm}$ ) in the ${ }^{1} \mathrm{H}$ NMR spectrum confirms that $(+)$-catechin is linked to the flavylium nucleus at $\mathrm{C}-4$ [26]. However, the position of linkage on the phloroglucinol moiety of catechin (C-6 or C-8) remains unknown. In addition, the ${ }^{1} \mathrm{H}$ NMR spectrum of 3 in $\mathrm{CD}_{3} \mathrm{OD}$ at $27^{\circ}$ shows duplicate signals for each proton which turn to single signals when the spectrum is recorded in DMSO at $60^{\circ}$. This points to restrictions

Table 1. ${ }^{1} \mathrm{H}$ NMR of rotamers $3_{1}$ and $3_{2}\left(400 \mathrm{MHz}, \mathrm{CD}_{3} \mathrm{OD} / \mathrm{TFA}, 27^{\circ}\right)$

\begin{tabular}{lllllllll}
\hline Flavylium & 5 & 6 & 8 & $2^{\prime}, 6^{\prime}$ & $3^{\prime}, 5^{\prime}$ & $4^{\prime} \mathrm{Me}$ & $3 \mathrm{Me}$ & \\
$\mathbf{3}_{\mathbf{1}}$ & $7.86, d(9.0)$ & $7.18, d^{*}$ & $7.27, s^{\dagger}$ & $8.45, d(8.7)$ & $7.18, d(8.7)$ & $3.94, s$ & $3.55, s$ \\
$\mathbf{3}_{\mathbf{2}}$ & $7.77, d(9.0)$ & $7.29, d^{*}$ & $7.32, s^{\dagger}$ & $8.34, d(8.7)$ & $7.13, d(8.7)$ & $3.91, s$ & $3.49, s$ & \\
Catechin & 2 & 3 & $4 \alpha$ & $4 \beta$ & 6 & $2^{\prime}$ & $5^{\prime}$ & $6^{\prime}$ \\
$\mathbf{3}_{\mathbf{3}}$ & $4.51, d(7.7)$ & $4.04, m$ & $3.05, d d(16.3,5.7)$ & $2.65, m$ & $6.64, s$ & $6.86, s$ & $6.61, d(8.1)$ & $6.65, d^{*}$ \\
$\mathbf{3}_{\mathbf{2}}$ & $4.55, d(7.7)$ & $3.98, m$ & $3.05, d d(16.3,5.7)$ & $2.65, m$ & $6.64, s$ & $6.86, s$ & $6.61, d(8.1)$ & $6.55, d^{*}$ \\
\hline
\end{tabular}

* No $J$ value is given because of superimposition in the spectra.

$\dagger$ The order may be reversed. 
in the rotation about the $\mathrm{C}-4 / \mathrm{C}-6$ or $\mathrm{C}-4 / \mathrm{C}-8$ link resulting in a mixture of rotamers. ${ }^{1} \mathrm{H}-{ }^{1} \mathrm{HCOSY}$ permits the differentiation between rotamers and allows the assignment of most of the signals (Table 1). Semi- empirical quantum mechanical calculations assuming a C-4/C-8 linkage and performed with different input values for the torsion angle about the $\mathrm{C}-4 / \mathrm{C}-8$ bond actually yielded two optimized conformations close in<smiles>Oc1cc(O)c2c(c1)O[C@H](c1ccc(O)c(O)c1)[C@H](O)C2</smiles>

\section{(+)-catechin}<smiles></smiles>

1<smiles></smiles>

2<smiles></smiles>

\section{1,3,6,8-tetrahydroxyxanthylium ion}<smiles>COc1ccc(-c2[o+]c3cc(O)ccc3c(-c3c(O)cc(O)c4c3O[C@H](c3ccc(O)c(O)c3)[C@H](O)C4)c2OC)cc1</smiles><smiles></smiles> 
A

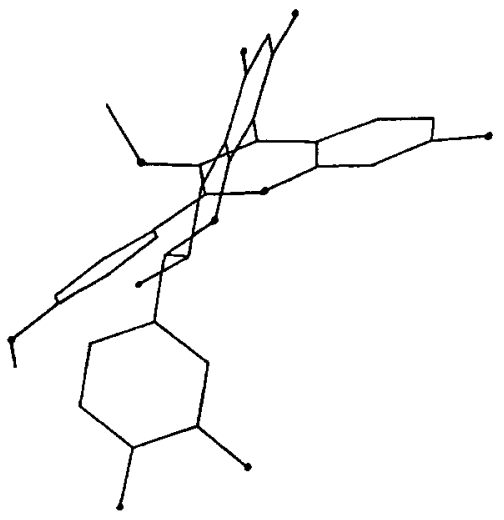

B

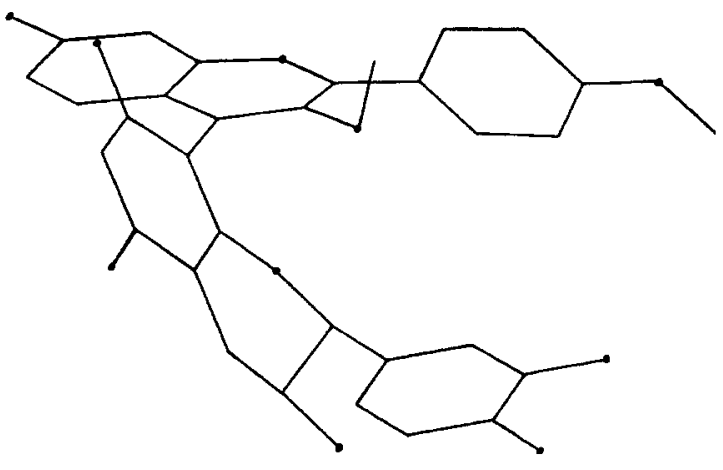

Fig. 1. Minimal-energy conformations of 3 . The torsion angle about the C-4 flavylium/C-8 catechin bond is $+56^{\circ}$ in (A) and -53 degrees in (B). We cannot specify which conformation corresponds to $\mathbf{3}_{\mathbf{1}}$ or $\mathbf{3}_{\mathbf{2}}$. $\mathbf{0}$, O-atom.

energy for which the flavylium C-3 to catechin C-9 torsion angle was approximately $+56^{\circ}$ and $-53^{\circ}$, respectively (Fig. 1).

The thermodynamic constants of the proton transfer $\left(K_{\mathrm{a}}\right)$ and hydration $\left(K_{\mathrm{h}}\right)$ equilibria were estimated for 1 and 3. The $\mathrm{p} K_{\mathrm{h}}$ value is the most relevant measure of the stability of a given anthocyanin in water. Its value is 2.22 for 1 and 3.10 for 3 at $25^{\circ}$ and $0.5 \mathrm{M}$ ionic strength. Moreover, $3\left(\mathrm{p} K_{\mathrm{a}}=4.5\right)$ was found significantly more acidic than $1\left(\mathrm{p} K_{\mathrm{a}}=4.9\right)$. The large difference in $\mathrm{p} K_{\mathrm{h}}$ values between 1 and 3 means that 3 is much more resistant than 1 to hydration. This should be mainly attributable to the electronic donating effect of the catechin moiety which is expected to weaken the electrophilic character of the flavylium nucleus but could also point to some copigmentation effect taking place in 3 and acting either in an intramolecular way (conformational folding) or in an intermolecular way (self-association).

Intramolecular copigmentation is usually considered the main mechanism of colour stabilization in natural anthocyanins having at least one of their glycosyl group substituted by an hydroxylated benzoic or cinnamic acid residue. This can be demonstrated by concentrationindependent NMR chemical shifts and long-range flavylium-aromatic acid NOE correlations [27]. Although self-association of common anthocyanins is usually weak (especially when the pigment is under the flavylium form), recent investigations [28, 29] have shown that petanin and alatanin $\mathrm{C}$, two natural anthocyanins whose chromophore is substituted on its 3-position by a disaccharide having one substituted cinnamyl residue on its nonreducing end, are able to form noncovalent dimers in which the flavylium nuclei are stacked on one another, the cinnamyl residues being either stacked on one another (petanin) or stacked on the flavylium nuclei (alatanin $\mathrm{C}$ ).

Although some kind of intramolecular copigmentation effect in 3 cannot be ruled out (the catechin moiety could be able to orient its catechol residue toward the flavylium chromophore and thereby significantly oppose the nucleophilic attack of water at C-2), the fact that the visible absorption band of $\mathbf{3}$ is hypsochromically shifted with respect to that of 1 is not consistent with this hypothesis. In addition, any flavylium-catechin molecular contact in 3 should make the ${ }^{1}$ H NMR signals of the catechin and flavylium moieties of 3 shift toward lower $\delta$ values with respect to the corresponding signals of 1 and catechin. This is true for the flavylium peaks but not for the catechin peaks which have roughly the same $\delta$ values in 3 and free catechin. Therefore, electronic effects should be mainly responsible for the improved stability of 3 in water with, in addition, the possible minor contribution of self-association of the flavylium nuclei.

Coupling with the 5,7-dihydroxy-3,4'-dimethoxyflavylium ion (2). This pigment is closer to the natural anthocyanins, especially those present in wines (Vitis vinifera) which all possess a $\mathrm{OH}$ group at the 5-position. 2 was found to react very slowly with $(+)$-catechin and, after four months, small amounts of two yellow pigments were detected in addition to several colourless products (probably formed upon degradation of 2). One of the yellow pigments displayed HPLC retention time (23.5 $\mathrm{min}$ ) and UV-visible spectrum (maximum around $440 \mathrm{~nm}$ in the HPLC conditions) that were identical to those of the 1,3,6,8-tetrahydroxyxanthylium ion (synthesized by condensation of phloroglucinol and phloroglucinaldehyde in strongly acidic conditions; see [30]). The 1,3,6,8-tetrahydroxyxanthylium ion was previously identified in stored grape juice [31] and is also liable to form upon degradation of 2 . The second yellow pigment too displayed a UV-visible spectrum consistent with a xanthylium chromophore (maximum around $404 \mathrm{~nm}$ in the HPLC conditions) but had a HPLC retention time much longer ( $39 \mathrm{~min}$ ) than that of the 1,3,6,8-tetrahydroxyxanthylium ion, probably because of a more heavily substituted chromophore.

The fact that 2 is less reactive than 1 toward catechin is consistent with previous findings [32] and may be attributable not only to steric hindrance in 2 due to the 
5-hydroxyl group but also to electronic effects. Indeed, semi-empirical quantum mechanics calculations (AM1 program) have shown that the presence of a $\mathrm{OH}$ group at C-5 markedly decreases the fraction of positive charge at C-4 and thus the electrophilic character of the flavylium ion.

\section{Acetaldehyde-mediated flavylium-catechin coupling}

Coupling with the 3,4'-dimethoxy-7-hydroxyflavylium ion (1). The ability of acetaldehyde to bridge two phloroglucinol-type aromatic rings has been reported. Since 1 is devoid of such a structure, adding acetaldehyde to a mixture of $\mathbf{1}$ and catechin is not expected to influence the coupling reaction. This was confirmed experimentally.

Coupling with the 5,7-dihydroxy-3,4'-dimethoxyflavylium ion (2). Adding acetaldehyde to a mixture of (2) and catechin resulted in a much faster formation of new pigments than in the absence of acetaldehyde. Indeed, after only one week of reaction, the concentrations of the two pigments formed were high enough to carry out the step of isolation upon semi-preparative HPLC. $20 \mathrm{mg}$ of a major pigment (4a) and $5 \mathrm{mg}$ of a minor pigment (4b) were thus obtained. $\mathbf{4 a}$ and $\mathbf{4 b}$ are probably the first pigments formed in a complex process of polycondensation. Indeed, at longer reaction time, their concentrations decreased and other pigments having greater HPLC retention times appeared. Ultimately, precipitation was observed in the reactional mixture. Similar observations have been previously reported with natural anthocyanins $[18,20-23]$.

The UV-visible spectra of $4 \mathbf{a}$ and $4 \mathbf{b}$ indicated that a flavylium chromophore was still present in both pigments. Moreover, the wavelengths of their absorption maxima in aqueous solution (pH 1) are 434 and $518 \mathrm{~nm}$ for $\mathbf{4 a}$ and 428 and $518 \mathrm{~nm}$ for $\mathbf{4 b}$, i.e. significantly higher than the ones of 2 (424 and $504 \mathrm{~nm}$ ). Upon FAB-mass spectrometric analysis of $\mathbf{4 a}$ and $\mathbf{4 b}$, a molecular ion at $m / z=615$ was observed for both pigments. This is consistent with one flavylium moiety linked to one catechin moiety through a $\mathrm{CH}_{3}-\mathrm{CH}$ bridge. ${ }^{1} \mathrm{H}$ NMR spectra of $4 \mathbf{a}$ and $\mathbf{4 b}$ allowed to assign most proton signals (Table 2) with the exception of the H-6 and $\mathrm{H}-8$ signals of the catechin and flavylium moieties that could not be distinguished. Then, from DEPT and ${ }^{1} \mathrm{H}-{ }^{13} \mathrm{C}$ correlation (HMQC and HMBC) spectra, the carbon signals of $4 a$ were readily assigned with the exception of the C-6 and C-8 signals of the catechin and flavylium moieties (Table 3).

Additional NMR experiments were undertaken to unambigously determine the position of the $\mathrm{CH}_{3}-\mathrm{CH}$ bridge. For 4a, a long-range NOE was observed between the doublet of the $\mathrm{H}-\mathrm{2}^{\prime}$ and $\mathrm{H}-\mathrm{\sigma}^{\prime}$ flavylium protons at $8.39 \mathrm{ppm}$ and the quartet of the methine proton of the bridge at $5.43 \mathrm{ppm}$. A similar correlation was observed for $\mathbf{4 b}$ with, in addition, a long-range NOE between the doublet of the $\mathrm{H}-2^{\prime}$ and $\mathrm{H}-\mathrm{G}^{\prime}$ flavylium protons at $8.37 \mathrm{ppm}$ and the doublet of the methyl protons of the bridge at $1.76 \mathrm{ppm}$. Molecular modelling experiments showed that the above-mentioned correlations were

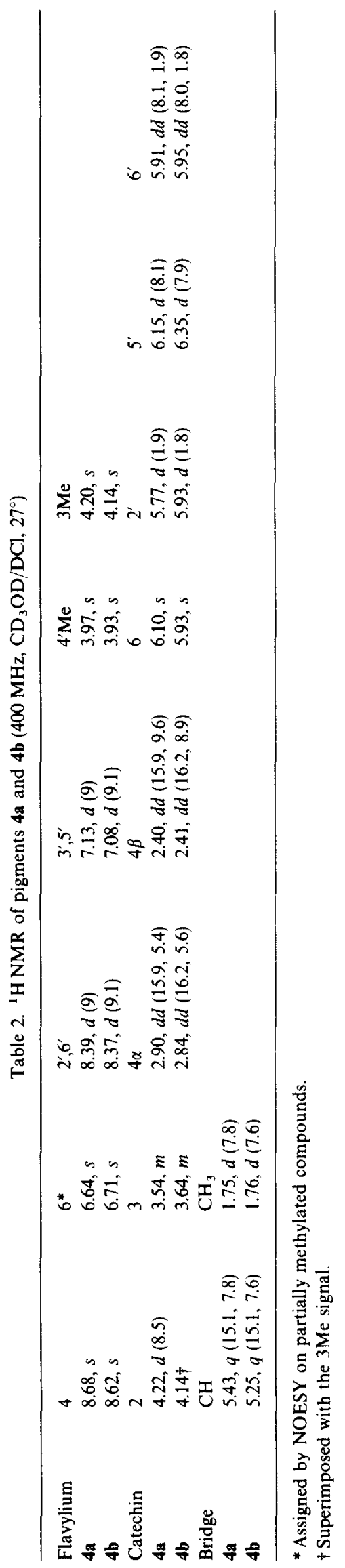


Table 3. ${ }^{13} \mathrm{C}$ NMR of pigment $4 \mathrm{a}\left(100 \mathrm{MHz}, \mathrm{CD}_{3} \mathrm{OD}-\mathrm{DCl}, 27^{\circ}\right)$

\begin{tabular}{llllllllllllllll}
\hline Flavylium & 2 & 3 & 4 & $4 \mathrm{a}$ & 5 & 6 & 7 & 8 & $8 \mathrm{a}$ & $1^{\prime}$ & $2^{\prime}, 6^{\prime}$ & $3^{\prime}, 5^{\prime}$ & $4^{\prime}$ & $4^{\prime} \mathrm{Me}$ & $3 \mathrm{Me}$ \\
& 162.5 & 148.5 & 130 & 114.5 & 156.5 & $104^{*}$ & 167 & $113^{*}$ & 153.5 & 123 & 135 & 116 & 167.5 & 56.5 & 57.5 \\
Catechin & 2 & 3 & 4 & $4 \mathrm{a}$ & $5,8 \mathrm{a}$ & 6 & 7 & 8 & $1^{\prime}$ & $2^{\prime}$ & $3^{\prime}$ & $4^{\prime}$ & $5^{\prime}$ & $6^{\prime}$ & \\
& 84 & 69 & 29 & 102.5 & 156.5 & $96.5^{*}$ & 156 & $108.5^{*}$ & 132 & 113.5 & 146 & 147 & 116 & 121 &
\end{tabular}

Bridge $\quad 1 \quad 2$

$27 \quad 19.5$

*Assigned by NOESY on partially methylated $\mathbf{4 a}$.

consistent with a bridging of the flavylium moiety at C-8 and allowed to rule out bridging at C-6. Thus, the H-6 signal of the flavylium nucleus was assigned at 6.64 and $6.71 \mathrm{ppm}$ for $\mathbf{4 a}$ and $\mathbf{4 b}$, respectively. From the HMQC spectrum of $4 a$, the flavylium C-6 and C-8 signals were then assigned at 104 and $113 \mathrm{ppm}$, respectively.

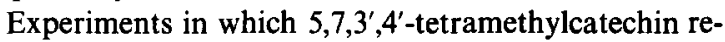
placed catechin were carried out in order to take advantage of additional NOE correlations involving the methyl groups at C-5 and C-7 and thereby determine the position of substitution of catechin. In this case, the larger steric hindrance strongly slowed down the coupling reaction and one month was required to obtain sufficient amounts of adducts.

If catechin is linked at C-6, one NOE is expected between $\mathrm{H}-8$ and the methoxy protons at $\mathrm{C}-7$, but if catechin is linked at C-8, two NOEs must occur between $\mathrm{H}-6$ and the methoxy protons at C-5 and C-7. The latter situation was observed with both adducts, thus pointing to a catechin moiety substituted at C-8. Therefore, both adducts display a catechin and a flavylium moieties substituted at their $\mathrm{C}-8$ positions and only differ by the configuration of the asymmetric carbon of the $\mathrm{CH}_{3}-\mathrm{CH}$ bridge.

The catechin H-6 signal was assigned at 6.10 and $5.93 \mathrm{ppm}$ for $\mathbf{4 a}$ and $\mathbf{4 b}$, respectively. From the HMQC spectrum of $4 \mathbf{a}$, the catechin C-6 and C-8 signals were then assigned at 96.5 and $108.5 \mathrm{ppm}$, respectively.

Flavylium-catechin interactions are expected to govern the geometry of the flavylium-catechin copigmentation complexes and thereby the $\mathrm{C}-8 / \mathrm{C}-8$ regioselectivity of the coupling reaction. From semi-empirical quantum mechanics calculations in vacuum, a possible face-to-face geometry for the flavylium 2-catechin copigmentation complex can be proposed (Fig. 2) in which both partners interact with each other through their whole tricyclic nuclei. Such arrangements should favour coupling reactions with closely packed transition states, thus leading to $\mathrm{C}-6 / \mathrm{C}-6$ or $\mathrm{C}-8 / \mathrm{C}-8$ linkages. On the contrary, C-6/ C-8 linkages would probably involve less thermodynamically favoured transition states displaying larger offsets between the flavylium and catechin moieties.

The thermal stability of the new pigments was investigated upon gradually raising the temperature of an aqueous solution of $4 \mathrm{~b}$ at $\mathrm{pH} 1$ from $20^{\circ}$ to $80^{\circ}$ with simulta-

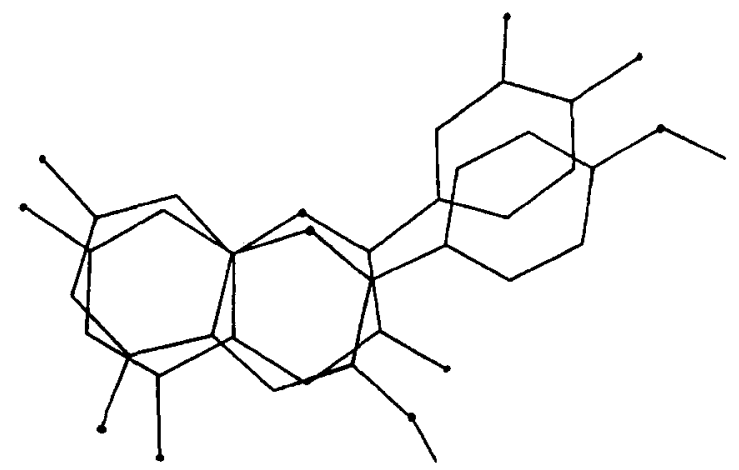

Fig. 2. Possible geometry of the flavylium $2 /$ catechin copigmentation complex obtained from semi-empirical quantum mechanics calculations (AM1) in vacuum. O-atom.

neous UV-visible absorption monitoring. Above $60^{\circ}$, slow irreversible spectral changes were observed which were consistent with the conversion of $\mathbf{4 b}$ into 2 . This was confirmed by HPLC analysis: when monitoring in the visible range, the chromatogram of a sample of $4 \mathrm{~b}$ kept at $70^{\circ}$ for $5 \mathrm{hr}$ showed only one peak corresponding to 2 . When monitoring in the UV range, additive peaks were observed, the main one corresponding to catechin. A kinetic study of the thermal degradation of $\mathbf{4 b}$ was carried out at $70^{\circ}$. From the apparent first-order increase in the visible absorbance at the wavelength of absorption maximum of 2 , the value of the corresponding rate constant was estimated to be $9( \pm 1) \times 10^{-3} \mathrm{~min}^{-1}$ (halflife: $77 \mathrm{~min}$ ).

The fact that the wavelength of the visible absorption maximum of $4 \mathrm{a}$ and $\mathbf{4 b}$ is $12 \mathrm{~nm}$ higher than that of $\mathbf{2}$ can be considered the first evidence of some inter- or intramolecular copigmentation effect. Moreover, ${ }^{1} \mathrm{H}$ NMR analysis in $\mathrm{CD}_{3} \mathrm{OD}$ (Fig. 3) show that the signals of the catechin and flavylium ring $B$ protons of $\mathbf{4 a}$ and $\mathbf{4 b}$ are strongly diamagnetically shifted (up to roughly 0.9-1.0 ppm and $0.8 \mathrm{ppm}$ for the $\mathrm{H}-2^{\prime}$ and $H-6^{\prime}$ catechin signals, respectively) with respect to the corresponding signals of 2 and catechin. This is the more impressive since the spectra were recorded in $\mathrm{CD}_{3} \mathrm{OD}$ where the $\pi$-stacking interactions are expected to be much weaker than in water. At $27^{\circ}$, NOESY spectra of $\mathbf{4 a}$ and $\mathbf{4 b}$ in 

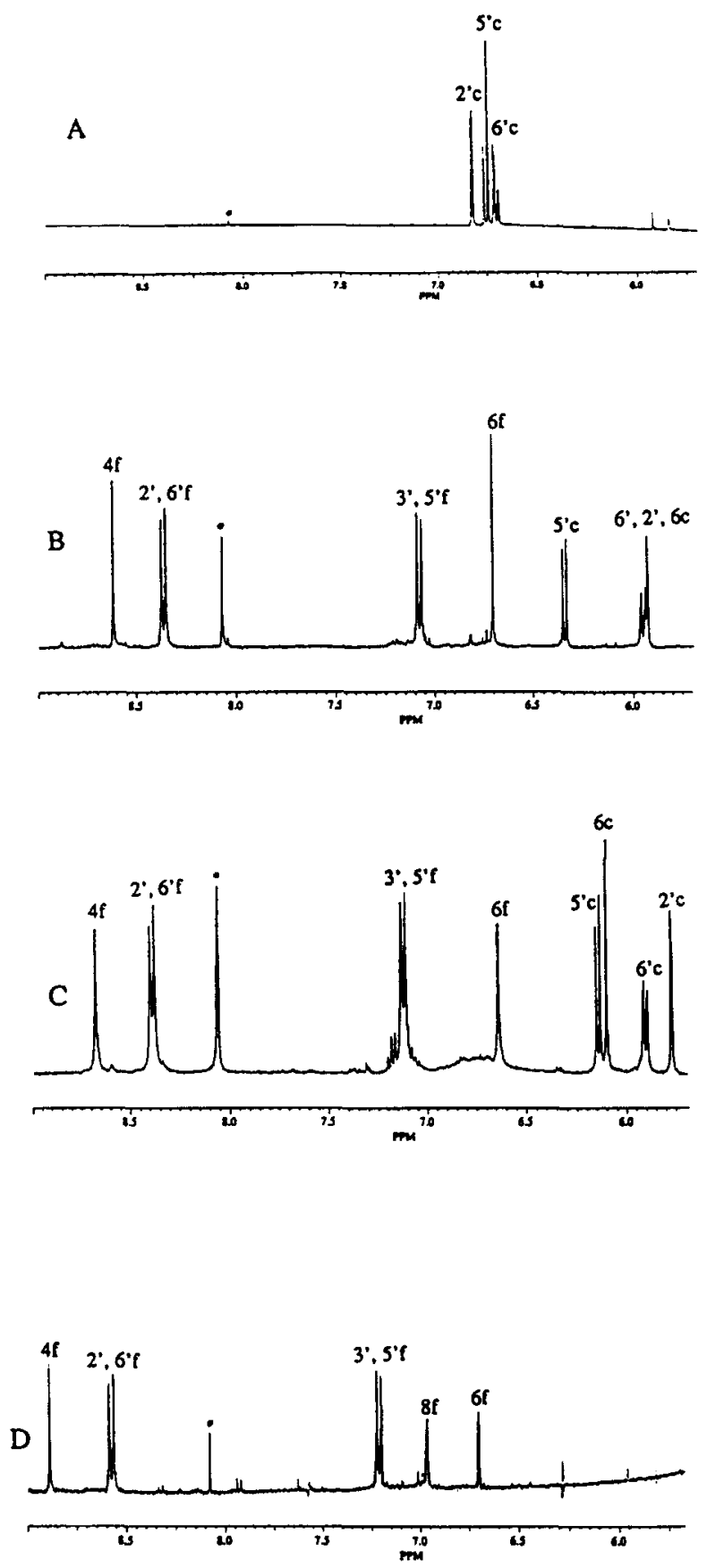

Fig. 3. ${ }^{1}$ H NMR spectra of catechin (A), 4a (B), 4b (C) and flavylium ion 2 (D) $\left(400 \mathrm{MHz}, \mathrm{CD}_{3} \mathrm{OD} / \mathrm{DCl}, 27^{\circ}\right)$. The signals of the catechin and flavylium ring $B$ protons of $\mathbf{4 a}$ and $\mathbf{4 b}$ are strongly diamagnetically shifted with respect to the corresponding signals of $\mathbf{2}$ and catechin. Formic acid (from HPLC eluents).

$\mathrm{CD}_{3} \mathrm{OD}$ and $\mathrm{D}_{2} \mathrm{O}$ failed to show long-range flavyliumcatechin NOEs. However, when the methanolic solution of $4 \mathrm{a}$ was cooled down to $-20^{\circ}$, several NOEs between the catechin and flavylium ring B protons clearly appeared. In fact, both $\left(\mathrm{H}-2^{\prime}, \mathrm{H}-6^{\prime}\right)$ and $\left(\mathrm{H}-3^{\prime}, \mathrm{H}-5^{\prime}\right)$ flavylium signals showed connectivities with the H-2',

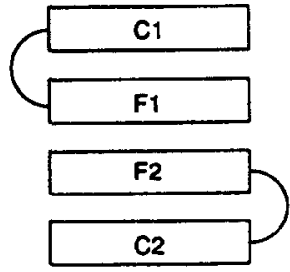

A

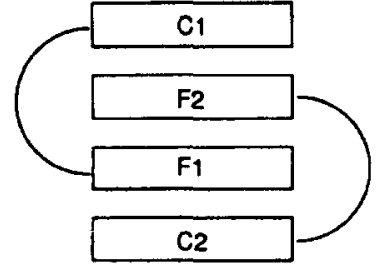

B
Fig. 4. Possible schematic structure of the dimeric flavyliumcatechin-acetaldehyde adduct. $\mathrm{C}=$ Catechin moiety, $\mathrm{F}=$ flavylium moiety.

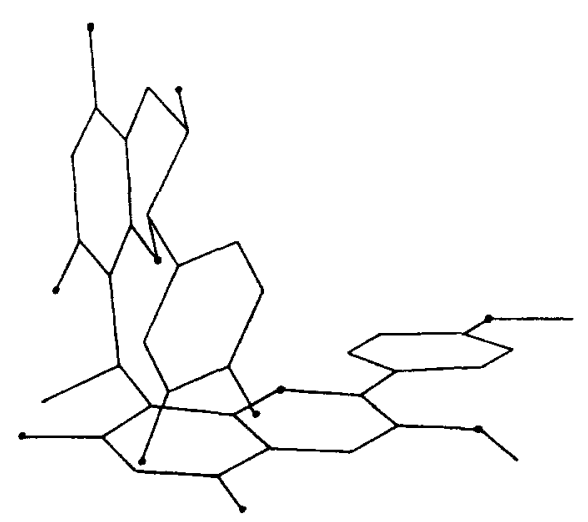

Fig. 5. Minimal-energy conformation of 4. The configuration of the bridging $\mathrm{CH}$ group is arbitrary. $\mathrm{O}$-atom.

$\mathrm{H}-\mathrm{5}^{\prime}$ and $\mathrm{H}-\mathrm{6}^{\prime}$ catechin signals. More surprisingly, weak long-range NOEs were observed within the flavylium signals, especially between $\mathrm{H}-6$ and $\mathrm{H}-4$ (separated by 4.9 angströms) on the one hand, and H-6 and the methyl protons at the $4^{\prime}$ position (separated by more than 12 angströms) on the other hand. In our opinion, such connectivities must reflect a noncovalent contact between two flavylium nuclei according to an arrangement which is head-to-tail with respect to the long axis of the chromophore and head-to-head with respect to its short axis (Fig. 4). Those results point to the noncovalent dimerization of $4 a$ according to one (or both) of the arrangements that are schematically depicted on Fig. 4: two flavylium nuclei are stacked on one another in an anti-parallel way and each catechin moiety interacts either with the flavylium nucleus to which it is connected (A) or with the flavylium nucleus of the other pigment molecule (B). Similar arrangements have already been suggested with the monoacylated anthocyanin alatanin C [28].

Semi-empirical quantum mechanical calculations on a flavylium 2-catechin-acetaldehyde adduct do not yield tight intramolecular stacks but rather open conformations (Fig. 5) in which the flavylium and catechin nuclei form a groove that could accommodate part of a second molecule of adduct. This seems to make arrangement B more favourable than arrangement $A$. 
Temperature-variation experiments in ${ }^{1} \mathrm{H}$ NMR and UV-visible spectroscopy were consistent with an exothermic dimerization process. For instance, raising the temperature of an aqueous solution of $4 \mathrm{~b}$ at $\mathrm{pH} 1$ from $15^{\circ}$ to $50^{\circ}$ resulted in a small but significant $(3 \mathrm{~nm})$ hypsochromic displacement in the visible band featuring partial dissociation of the dimer. More convincingly, a temperature variation from $20^{\circ}$ to $45^{\circ}$ caused most NMR signals ( $500 \mathrm{MHz}, \mathrm{D}_{2} \mathrm{O}-\mathrm{DCl}$ as solvent, $\mathrm{CD}_{3} \mathrm{OD}$ as internal reference) of the flavylium and catechin aromatic protons of $4 a$ to shift to higher values (paramagnetic shifts). The larger shifts were $56 \mathrm{~Hz}$ for the flavylium $\mathrm{H}-2^{\prime}$ and $\mathrm{H}-6^{\prime}$ signals, and $42 \mathrm{~Hz}$ for the catechin H-5' signal.

Visible absorbance vs pigment concentration plots (Beer's plots) were constructed for pigments 2 and 4a. However, in the relatively narrow concentration range which could be investigated $\left(8 \times 10^{-6}\right.$ to $\left.1.2 \times 10^{-4} \mathrm{M}\right)$, no significant deviation from linearity could be evidenced.

Additional evidence for self-association was gained when the visible absorbance of equilibrated aqueous solutions of $4 \mathbf{a}$ and $\mathbf{4 b}$ (at the wavelength of flavylium absorption maximum) was plotted as a function of the $\mathrm{pH}$ in order to estimate the overall thermodynamic constant of the flavylium-quinonoidal base and flavyliumhemiacetal equilibria $\left(K_{\mathrm{h}}+K_{\mathrm{a}}\right)$. Clearly, no satisfactory fitting of the experimental curves could be obtained with a theoretical law assuming single proton transfers. On the contrary, perfect fittings were obtained when two successive proton transfers were assumed. The corresponding apparent $\mathrm{p} K$ values were estimated to be 2.6 and 3.9 for $\mathbf{4 a}$, and 3.0 and 4.6 for $\mathbf{4 b}$ at $25^{\circ}$ and $0.5 \mathrm{M}$ ionic strength. In comparison, the $\mathrm{p} K_{\mathrm{h}}$ value of 2 is 2.80 in the same conditions. In the $\mathrm{pH}$ range investigated (from 2 to 5), deprotonation of the neutral quinonoidal bases to give the anionic quinonoidal bases ( $\mathrm{p} K_{\mathrm{a}}$ higher than 6 ) and deprotonation of $(+)$-catechin (first $\mathrm{p} K_{\mathrm{a}}$ equal to 8.64 at $25^{\circ}$ and $0.1 \mathrm{M}$ ionic strength [33]) are not to be considered. Therefore, the only reasonable explanation for this abnormal behaviour seems to assume that both $4 \mathrm{a}$ and $\mathbf{4 b}$ are present as noncovalent dimers $(\mathrm{AH})_{2}$ in acidic aqueous solution (pigment concentration $\mathrm{ca} 10^{-4} \mathrm{M}$ ) and that raising the $\mathrm{pH}$ leads to two successive proton transfers, the first one giving the (AH, A) and $(\mathrm{AH}, \mathrm{B})$ dimers and the second one giving a mixture of twice deprotonated dimers that may include $(A)_{2},(A, B)$ and (B) ${ }_{2}$. Note that some dimers, especially the ones involving the nonplanar hemiacetal (B), may further dissociate according to a $\mathrm{pH}$-independent process.

The above-given $\mathrm{p} K$ values show that minor pigment 4b is significantly more resistant than $4 \mathbf{a}$ to fading (hydration). Note that the stability of the flavylium chromophores in pigments 4 cannot be quantitatively compared to that of pigments 1 to 3 since the latter are monomeric whereas the former are essentially dimeric. However, a comparison of the visible absorption spectra of 3 and 4 at different $\mathrm{pH}$ values (Fig. 6) points to a colour-stabilizing mechanism particularly efficient in pigments 4. For instance, whereas an equilibrated solution of 3 at $\mathrm{pH} c a 4$ is almost colourless (the same is true
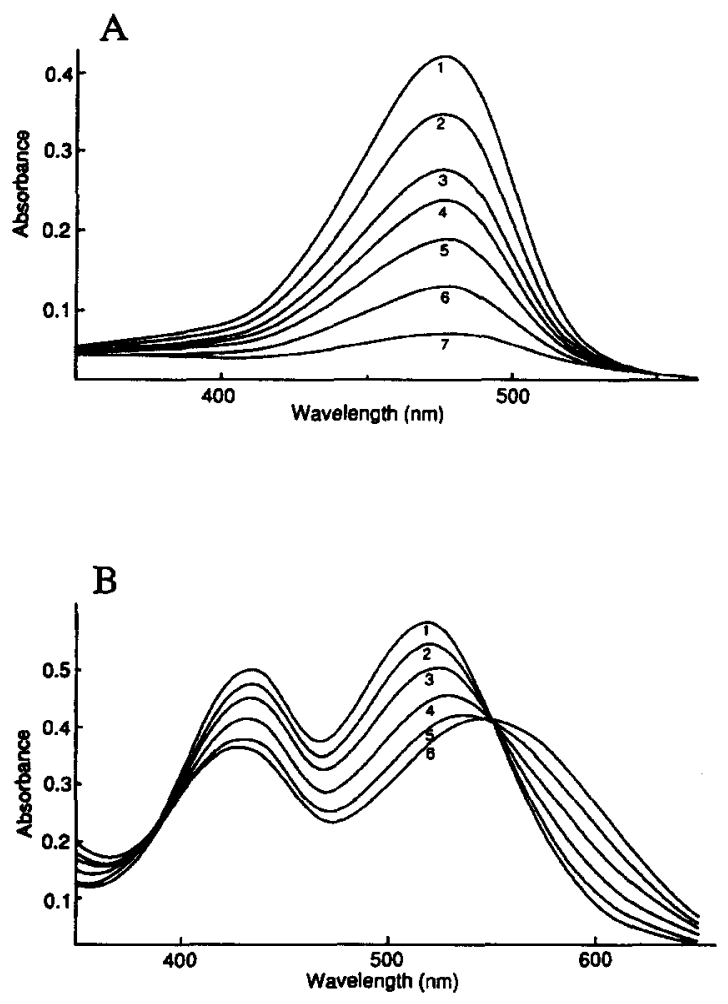

Fig. 6. Changes in the visible spectrum of 3 (A) and $4 a(B)$ as a function of $\mathrm{pH}$. (A): the spectra have been recorded at $\mathrm{pH}$ $1.5(1), 2.5(2), 2.8(3), 3.0(4), 3.2(5), 3.5(6), 4.0(7)$. (B): the spectra have been recorded at $\mathrm{pH} 2.2(1), 2.8(2), 3.3(3), 3.8(4), 4.2(5), 4.6$ (6).

for 1 and 2 which are even more sensitive than 3 to hydration), a large percentage of pigments 4 remains under coloured forms between $\mathrm{pH} 4$ and 5 .

In conclusion, noncovalent dimerization of flavyliumcatechin-acetaldehyde adducts itself may be followed by covalent coupling (C-6/C-6 linkage) between the two monomers in the same way as flavylium-catechin copigmentation is followed by $\mathrm{C}-8 / \mathrm{C}-8$ covalent coupling. The so-formed oligomeric structures would have two flavylium and two catechin residues connected through C-6/C-6 and C-8/C-8 linkages and could be the early products formed in a complex polymerization process ultimately leading to precipitation as observed in our reactional mixtures and in old red wines.

\section{EXPERIMENTAL}

Analytical HPLC. A $5 \mu \mathrm{m}$ LiChrospher $60 \mathrm{RP}$-select B column $(125 \times 4 \mathrm{~mm})$ protected by a LiChrospher $60 \mathrm{RP}$ guard column was used. The solvents were $5 \%$ aqueous formic acid (A) and 5\% formic acid in acetonitrile-water (1:1) (B). For elution, a linear gradient from $5 \%$ to $40 \%$ B over $50 \mathrm{~min}$ and 40 to $100 \%$ B over $20 \mathrm{~min}$, was established with a flow rate of $1.5 \mathrm{ml} \mathrm{min}{ }^{-1}$. Detection was monitored at 280 and $510 \mathrm{~nm}$ with a diode array detector coupled to a data treatment station. 
Semi-preparative HPLC. 3 was isolated on a $10 \mu$ Nucleosil C18 column $(25 \times 1 \mathrm{~cm})$ connected to the diode array detector . For elution, a linear gradient was established from $15 \%$ to $50 \%$ A over 90 min with a flow rate of $2.5 \mathrm{ml} \mathrm{min}^{-1}$.

Semi-preparative liquid chromatography. Isolation of the condensation products $\mathbf{4 a}$ and $\mathbf{4 b}$ was performed on a glass column $(15 \times 3 \mathrm{~cm})$ filled with LiChrospher R P-18 (40-63 $\mu \mathrm{m}$ ). Elution was carried out with $5 \%$ to $40 \%$ ethanol in $5 \%$ aqueous formic acid. Compressed air was applied at the top of the column to maintain a flow rate of $\mathrm{ca} 2.5 \mathrm{ml} \mathrm{min}^{-1}$.

NMR spectra. NMR spectra were recorded at $27^{\circ}$, chemical shifts $\delta$ in ppm with respect to $\mathrm{SiMe}_{4}$ as external standard (internal reference: $\mathrm{MeOH}, \delta=3.30$ ); coupling constants $J$ in $\mathrm{Hz}$.

$U V$-visible spectra. UV-visible spectra were recorded with a diode-array spectrophotometer fitted with a quartz cell (optical pathlength: $1 \mathrm{~cm}$ ) equipped with a stirring magnet. The cell was thermostated at $25( \pm 0.1)^{\circ}$ by use of a water-thermostated bath. Ionic strength was fixed at $0.5 \mathrm{M}$ by $\mathrm{NaCl}$.

Data analysis. The curve fittings were carried out on using the Kaleida Graph program.

Semi-empirical quantum mechanical calculations. Semiempirical quantum mechanical calcns were performed in vacuum using the Hypercube program (Inc., Waterloo, $\mathrm{CA})$ in the AM1 parametrization.

Materials. ( +)-Catechin was purchased from Aldrich. 2,4-Dihydroxybenzaldehyde and 2,4,6-trihydroxybenzaldehyde were from Janssen (Belgium). 2,4'-Dimethoxyacetophenone was synthesized following a procedure recently described [34] but using 4-methoxyacetophenone instead of 4-hydroxyacetophenone.

3,4'-Dimethoxy-7-hydroxyflavylium chloride (1) [24]. 1 was synthesized upon condensation of 2,4'-dimethoxyacetophenone with 2,4-dihydroxybenzaldehyde in ethylacetate under bubbling of hydrogen chloride (yield: $35 \%$ ). The deep-red ppt. was collected and thoroughly washed with ethylacetate; its purity was checked by reverse-phase HPLC analysis, FAB-MS $(m / z=282.9)$ and ${ }^{1}$ H NMR (200 MHz, CD 3 OD-TFA (98:2)): 8.96 (s, H-4), $8.66\left(d, J=9.2, \mathrm{H}-2^{\prime}, \mathrm{H}-6^{\prime}\right), 8.09(d, J=8.9, \mathrm{H}-5), 7.47(d$, $J=2.1, \mathrm{H}-8), 7.42(d d, J=8.9,2.1, \mathrm{H}-6), 7.22(d, J=9.2$, H-3', H-5'), $4.24\left(s, \mathrm{CH}_{3}-3\right), 3.98\left(\mathrm{~s}, \mathrm{CH}_{3}-4^{\prime}\right) . \lambda_{\max }\left(\mathrm{H}_{2} \mathrm{O}\right)=$ $488 \mathrm{~nm}$.

5,7-Dihydroxy-3,4'-dimethoxyflavylium chloride (2). 2 was synthesized upon condensation at room temperature of 2,4'-dimethoxyacetophenone with 2,4,6-trihydroxybenzaldehyde in formic acid under $\mathrm{HCl}$ bubbling (yield: $73 \%$ ). The soln was concd to dryness and the residue washed with acetone; its purity was checked by reverse-phase HPLC, FAB-MS $(m / z=299.2)$ and ${ }^{1} \mathrm{H}$ NMR (200 MHz, CD 3 OD-TFA (98:2)): 8.84 (broad $s, \mathrm{H}-4), 8.53\left(d, J=9.3, \mathrm{H}-2^{\prime}, \mathrm{H}-6^{\prime}\right), 7.16(d, J=9.2$, H-3', H-5'), 6,90 (dd, $J=2,0.9, \mathrm{H}-8), 6.68(d, J=2, \mathrm{H}-6)$, $4.18\left(s, \mathrm{CH}_{3}-3\right), 3.94\left(s, \mathrm{CH}_{3}-4^{\prime}\right) . \quad \lambda_{\max }\left(\mathrm{H}_{2} \mathrm{O}\right)=424$ and $504 \mathrm{~nm}$.

Methylation of catechin. Methylation of catechin was performed with trimethylsilyldiazomethane according to
[35]. Its purity was checked by reverse-phase HPLC and ${ }^{1} \mathrm{H}$ NMR (200 MHz, $\mathrm{CDCl}_{3}$ ): 6.92 (dd, $J=1.8,8.1, \mathrm{H}-6$ '); $6.98\left(d, J=1.8, \mathrm{H}-2^{\prime}\right) ; 6.90\left(d, J=8.0, \mathrm{H}-5^{\prime}\right) ; 6.15(d, J=$ $2.2, \mathrm{H}-8) ; 6.11(d, J=2.2, \mathrm{H}-6) ; 4.7(d, J=8.4, \mathrm{H}-2)$; 4.07 ( $m, \mathrm{H}-3) ; 3.90$ (s, Me-3',4'); 3.81 (s, Me-5); 3.76 $(s, \mathrm{Me}-7) ; 3.08(d d, J=16.3,5.6, \mathrm{H}-4 \alpha) ; 2.59(d d, J=16.3$, 9.1, $\mathrm{H} 4 \beta$ ).

Estimation of the thermodynamic constants of hydration $\left(K_{\mathrm{h}}\right)$ and proton transfer $\left(K_{\mathrm{a}}\right)$. The value for the overall thermodynamic constant $K_{\mathrm{h}}+K_{\mathrm{a}}$ (usually approximated to $K_{h}$ ) was deduced from a plot of the visible absorbance of equilibrated pigment solutions at the wavelength of flavylium absorption maximum as a function of $\mathrm{pH}$. The $K_{\mathrm{a}}$ value was obtained from $\mathrm{pH}-\mathrm{jump}$ experiments with consecutive curve fitting of the plot of the apparent rate constant of hydration (first order) vs final $\mathrm{pH}$ (for details, see ref. [36]).

Copigmentation experiments. UV-visible spectra of aqueous solutions of flavylium ions 1 and $\mathbf{2}$ were recorded for increasing concns of catechin at strongly acidic and/or weakly acidic $\mathrm{pH}$ values. From the visible absorbance (at a fixed wavelength in the visible range) $v s$ catechin concentration plots, the copigmentation binding constants could be estimated (for details, see ref. [34]).

Coupling reactions. Model solutions were prepared as follows: the flavylium ion and $(+)$-catechin were dissolved in $4 \mathrm{ml}$ of $20 \%$ aqueous acetic acid $(\mathrm{pH}=2)$. In the presence of acetaldehyde $(1.8 \mathrm{mM})$, the initial concentration of both polyphenols was $1 \mathrm{mM}$. In the absence of acetaldehyde, two equivalents of flavylium ion were used. The same procedure was followed with 5,7,3',4'-tetramethylcatechin replacing catechin. The samples were stored in darkness at room temp. Samples were taken periodically and analysed by HPLC.

\section{REFERENCES}

1. Dangles, O. and Brouillard, R. (1992) Can. J. Chem. 70, 2174.

2. Liao, H., Cai, Y. and Haslam, E. (1992) J. Sci. Food Agric. 59, 299.

3. Brouillard, R. and Dangles, O. (1994) Food Chem. 51, 365.

4. Somers, T. C. (1971) Phytochemistry 10, 2175.

5. Somers, T. C. and Evans, M. E. (1977) J. Sci. Food Agric. 28, 279.

6. Somers, T. C. (1966) Nature 209, 368.

7. Jurd, L. (1969) Am. J. Enol. Vitic. 20, 191.

8. Haslam, E. (1980). Phytochemistry 19, 2577

9. Jurd, L. and Wais, A. C. (1965) Tetrahedron 21, 1471 .

10. Timberlake, C. F. and Bridle, P. (1976) Am. J. Enol. Vitic. 27, 97.

11. Singleton, V. L. and Esau, P. (1969) Advan. Food Res. Suppl. 1, 1.

12. Jurd, L. and Somers, T. C. (1970) Phytochemistry 9, 419.

13. Hillis, W. E.and Urbach, G. (1959) J. Appl. Chem. 9, 474. 
14. Joslyn, M. A. and Comar, C. L. (1941) Ind. Eng. Chem. $33,919$.

15. Wildenradt, H. L. and Singleton, V. L. (1974) Am. J. Enol. Vitic. 25, 119.

16. Ribéreau-Gayon, P., Pontallier, P. and Glories, Y. (1983) J. Sci. Food Agric. 34, 505.

17. Timberlake, C. F. and Bridle, P. (1977) J. Sci. Food Agric. 28, 539.

18. Bakker, J., Picinelli, A. and Bridle, P. (1993) Vitis 32, 111.

19. Picinelli, A., Bakker, J. and Bridle, P. (1994) Vitis 33, 31.

20. Garcia Viguera, C., Bridle, P. and Bakker, J. (1994) Vitis 33, 37.

21. Roggero, J. P., Coen, S., Archier, P. and RochevilleDivorne, C. (1987) Conn. Vigne Vin 21, 163.

22. Green, R. C. and Mazza, G. (1988) Can. Inst. Food Sci. Technol. 21, 537.

23. Santos Buelga, C., Bravo-Haro, S., Ortega Meder, D., Guerra, T. and Rivas-Gonzalo, J. C. (1995) In Polyphenols 94 (Brouillard, R., Jay, M., Scalbert, A. eds). INRA editions 203.

24. Wigand, M. C., Dangles, O. and Brouillard, R. (1992) Phytochemistry 31, 4317.
25. Jurd, L. (1969) Tetrahedron 25, 2367.

26. Jurd, L. (1967) Tetrahedron 23, 1057.

27. Yoshida, K., Kondo, T. and Goto, T. (1992) Tetrahedron 48, 4313.

28. Yoshida, K., Kondo, T. and Goto, T. (1991) Tetrahedron Letters 32, 5579.

29. Nerdal, W. and Andersen, Ø. M. (1992) Phytochemical Analysis 3, 182.

30. Dangles, O. and Brouillard, R. (1994) New J. Chem. 18, 287.

31. Hrazdina, G. and Borzell, A. J. (1971) Phytochemistry 10, 2211

32. Iacobucci, G. A. and Sweeny, J. G. (1983) Tetrahedron 39, 3005.

33. Kennedy, J. A., Munro, M. H. G., Powell, H. K. J., Porter, L. J. and Foo, L. Y. (1984) Aust. J. Chem. 37, 885.

34. Dangles, O. and Elhajji, H. (1994) Helv. Chim. Acta 77, 1595.

35. Aoyama, T., Terasawa, S., Sudo, K. and Shioiri, T. (1984) Chem. Pharm. Bull. 32, 3759.

36. Dangles, O., Saito, N. and Brouillard, R. (1993) J. Am. Chem. Soc. 115, 3125. 